\title{
AdDendum To "The OCEANOGRAPHy TeXT PatTern: A REVIEW AND COMPARISON OF INTRODUCTORY OCEANOGRAPHY TEXTS"
}

\author{
By Richard W. Spinrad*
}

$S$ Q view of Oceanography texts last year (Spinrad, 1996), The Oceanography Society was contacted by two authors. In one case we were asked to include a previously overlooked text, and in the other case, the author was concerned that the text which had been provided by their publisher was not the most recent college-level version. Respectively, these two texts, reviewed here as an addendum to the original assessment (and using the original criteria for review), are

\section{David A. Ross}

Introduction to Oceanography

HarperCollins, 1996, ISBN 0-673-46938-7

2. Alyn C. Duxbury and Alison B. Duxbury An Introduction to the World's Oceans, 5th Edition

Wm. C. Brown Publishers, 1997. ISBN 0697-28273-2

Ross ${ }^{\circ}$ text follows a rather traditional approach to presenting the field of oceanography. It is generally a sound and informative book. Using the same criteria as developed for the previous review of texts, Ross' volume shakes out as follows:

Tides-This section is included as part of the treatment of waves. The discussion of forces is very (perhaps too) simplistic, but the use of graphics is very good. There is minimal treatment of dynamic theory, and no real data are included. One unique aspect is the treatment of tidal friction in the context of paleoceanography. The whole discussion on tides covers only about five pages and there is nothing on amphidromic points or cotidal lines. The treatment of tides is slightly disappointing.

Primary Production-Ross takes an ecosystem approach which invokes a strong element

Richard W. Spinrad. Consortium for Oceanographic Research and Education, 1755 Massachusetts Ave. NW, Washington, DC, 20036-2101, USA.

* The opinions expressed in this article are solely those of the author, not that of TOS or CORE. of disciplinary integration. Other textbook authors could learn a lot from this approach. There is an excellent treatment of photosynthesis, production, respiration, compensation depth, nutrient supply, and physical controls. There are also good comparisons of photosynthesis and chemosynthesis, and very nice treatments of geographic variability and general measurement techniques. One interesting point is the inclusion of a box on the iron experiments conducted in the Pacific, although this appears in the chapter on climate, and there is no cross reference in the chapter on productivity. Nevertheless, Ross" treatment of primary production is a strong point in the text.

El Niño-Ross' treatment of ENSO is very clear and succinct, including a very fair description of the methods of observation and the forecast limitations. He also includes a good discussion of the global implications of El Niño. One change I would recommend is more abundant inclusion of El Niño throughout the rest of the text. I also believe the references specific to El Niño, at the end of the chapter, are not adequately current (the most recent is from 1986).

Hydrothermal vent biota-This is an excellent piece of this textbook. Along with some wonderful photographs, Ross has included a nice definition of the wonder of these discoveries, and their implications for understanding life in extreme environments. He also blends this section with a nice discussion on chemosynthesis (see above), and a very good set of references at the end of the chapter. I really enjoyed reading this section.

Biodiversity-Except in terms of a general discussion of biological communities, this section is insufficient.

Acoustic Thermometry-This text is one of the very few (compared to those reviewed previously) that has a section on this subject. Ross also includes a discussion on the relatively new field of acoustic tomography. The Heard Island experiment is described reasonably well, with, perhaps, a bit too much emphasis on the environmental debates of using sound sources in ocean waters. Overall, Ross treats the subject of acoustics fairly and fully.

Optics-Ross has given another fair and accurate treatment of this subject, indepen- dently, and in the context of biological production. My only objection is that the section is called out as a separate box, thus suggesting that the subject is not central to oceanography.

References - The average number of references per chapter is 15 , with the oldest being from 1912. the newest from 1993, and the mean age being 1985 . The disturbing additional bit of information is that most of the policy-related chapters include virtually no references after 1993. In fact, the chapter dealing with the Law of the Sea has no references since 1989. Otherwise. this text is comparable to most of the others reviewed previously.

General Comments-This book includes some unique elements. Ross has included separate sections on the ocean's role in global climate change, as well as chapters on marine archaeology. marine pollution, and Law of The Sea. The text includes over 50 boxes on subjects of a scientific, technological, or general interest. There is good use of color graphics, photographs. and generally a nice mix of schematics and real data. There is a notable bias toward material from scientists at Woods Hole Oceanographic Institution (12 of 20 randomly selected figures had WHOI credits). Each chapter includes a very readable and short introduction and at the end. a good summary. The review questions at the end of each chapter are too regurgitative but might be good for quizzes. Key terms. highlighted in the text, are helpful. albeit a bit numerous. The lists of further reading tend to be nontechnical, with a heavy emphasis on Oceanus. Scientific American. and other texts (each reference includes an informative 1-line description). It would be nice to see more technical journals included. The text's appendices are not particularly helpful. They include a list of conversion tables and description of the metric system, a good (but not great) glossary (e.g., it doesn't include "biogeochemistry" or the Ocean Drilling Program), and a list of references, the relevance of which is unclear.

Conclusion-Ross 'text is good overall. with some sections that are outstanding. The reader is well advised to carefully review all sections, since some fell short of providing the most current or complete information. 
The Duxburys text, hot off the presses, is an extremely impressive and useful book for a college level class. While the version reviewed in the previous assessment was not appropriate for an undergraduate course, this one is outstanding. So much about it reflects the Duxburys' diligence in researching topics, and attention to detail. Let me march through the subjects reviewed:

Tides-This subject is covered in a whole chapter of some twenty pages, and specifically geared to students who have little or no understanding of vectors. The chapter starts with a good definition of key tidal characteristics: temporal and spatial patterns and variability (including tidal currents). There is a very nice breakout of equilibrium and dynamic theory: in the former, the authors do a nice job of holding the students' hands through some simplified explanations. The section on dynamic tide analysis is impressive in its ties to previous readings on shallow water waves and the Coriolis effect. I would have liked, however, to see a tabular breakout of tidal components. The coverage of cotidal lines and amphidromic points, done in the context of standing waves (including a method to calculate the natural period of oscillation in a tidal basin) is quite clear. The Duxburys' discussion of the capabilities, benefits and detriments of harnessing tidal energy is, in two words, excellent and fair. I also liked their presentation on tides with respect to estuarine mixing and flushing. In summary, this treatment of tides is the best of any of the eight texts now reviewed.

Primary Production-Again, this is a thorough and accurate section. Good, clear definition of gross and net production lead smoothly and logically into a discussion of controls. While there is a disappointing paucity of real data in this section. I was encouraged by the brief, but accurate mention of the recent work on trace metal controls. The discussion continues to include a very nice synopsis of average global distributions of production (including numbers) and a good definition of zonally dependent seasonal variability. Table 14.2, showing relative gross production on land and in the ocean (for different environments), is terrific. The section on measurement methods is short but complete and up-to-date.

El Niño-I would put the Duxburys' coverage of El Niño near the top, for all of the texts, mostly by virtue of their comprehensiveness. Physical processes, temporal/spatial scales, current state of forecast capabilities, and the concepts of teleconnections are all included in the text. This is one case where they make nice use of real-world data, and, albeit subtly, they make mention of the relationship between El Niño detection and background global warming signatures. One particularly noteworthy aspect of their coverage of El Niño is their mention, throughout the book, of the potential impact of the phenomenon on a wide range of such societally important issues as fish stocks, $\mathrm{CO}_{2}$ exchange, and formation of North Atlantic cold water masses.

Hydrothermal vent biota-To their credit the authors include some mention of this subject in their discussion of primary production (in the context of chemosynthesis cf. photosynthesis). They include a few photos, but none as stunning as contained in some of the other texts. Generally, the coverage is good my only complaint is that the excitement of the discovery of hydrothermal vent biota and the potential implications in studies of the origins of life are not appropriately conveyed.

Biodiversity-This subject, while mentioned in passing in the preface, is not specifically called out in the body of the text. There are faint allusions by virtue of discussion on genetic manipulation and nonindigenous species, but the coverage overall is lacking.

Acoustic Thermometry-The reader is reminded that in the previous review fewer than one-half of the texts discussed this subject, and only one did it well. The Duxburys' excel in this coverage. They include an outstanding definition of the concepts of long-range acoustic transmission and the connection to integrated temperature measurement (as well as a very fair discussion on the marine mammal-related concerns for this research). Their section even has brief mention of the recent Transarctic Acoustic Propagation experiment. A noteworthy related point is their inclusion of a separate section on acoustic tomography (including some discussion on moving source tomography!).

Optics-This coverage is a bit disappointing. While generally accurate, the description of the physics behind water color is insufficient. My main complaint, however, is that the definition of the technology for optical measurement is about 20 years out of date (e.g., hand-held photometers with analog voltmeter readouts). This section has not been researched and updated as well as most of the rest of the text.

References-The Duxburys make extensive use of references from the general scientific literature (Scientific American, Oceanus) with a peppering of technical references (Science) and an impressive set of references to the classic oceanographic texts (Shepard, Bascom, Parsons/Takahashi/Hargrave, Pickard/Emery, Riley/ Chester, Bowditch, etc.). Students should have no problem finding most of the references included in this text. That's a real plus! The numbers are also very good: an average of 23 references per chapter, with a mean date of 1988 (in the random check of five chapters the oldest reference was from 1953 and the newest from 1996). But, perhaps, most impressive about the references is the inclusion of an ex- tensive set of World Wide Web Home Pages. Regardless of how ephemeral the individual URLs might be, this is an enormously valuable reference tool, and the Duxburys are to be credited for taking a lead among oceanography texts in providing this service. $\dagger$

General Comments--This book is a joy to read! The writing is clear and concise, the use of graphics is quite aesthetically pleasing, and there is an outstanding mix of photos, satellite images, schematics, and plots of data. Each chapter begins with a literary quote and a short intro, both of which are attractive. All of the chapters include good, short summaries, and an adequate list of key terms. Most of the chapters include a section on practical considerations (e.g., Ocean Thermal Energy Conversion, coastal development, fisheries, etc.) which are generally important, relevant, and thought provoking. Boxes for new techniques and new projects (with most of the emphasis on the former) represent an excellent choice of topics, from remote sensing, to the Navy's Sound Surveillance System (SOSUS), to sidescan technology, to viruses, and even the Great Pacific Sneaker Spill. Overall, the Duxburys have done a very nice job of including current interest items throughout the text (including very recent information on cholera). They"ve also taken a nontraditional view toward inclusion of environmental concerns, by placing that chapter in the middle of the book (following the chapter on coastal processesgood thinking!), rather than at the end of the volume (which for many texts implies that this subject is nothing more than an afterthought). Each chapter ends with study questions that are comprehensive but mostly of a review nature. Some chapters also have study problems, which, while almost exclusively mathematical in form, really do test the understanding of the students; there should be more of these. In summary, had this volume been available during the initial review it would have, undoubtedly ranked in the top group.

The conclusion on these two additional texts is that they are both good. The material which Ross' text covers, is generally dealt with well, but the reader is advised to check carefully on individual subjects (he can be a bit spotty). I am particularly impressed with the Duxburys' volume. This is more than a text book .... it is also a good reference document. In fact, I will think seriously about using this new volume in my own course next time around. I highly recommend it for its quality, currency, and completeness.

$\dagger$ In the undergraduate oceanography course I taught this spring, approximately $90 \%$ of my students indicated that they have access to, and use the Web for course-related research. 